\title{
Antimicrobial resistance patterns of Haemophilus influenzae isolated from patients with meningitis in São Paulo, Brazil
}

S.T. Casagrande ${ }^{1}$, E.J. Vicente ${ }^{2}$,

I.M. Landgraf ${ }^{1}$ and A.M.M. Kobata ${ }^{1}$
1Seção de Bacteriologia, Instituto Adolfo Lutz, São Paulo, SP, Brasil ${ }^{2}$ Departamento de M icrobiologia, Instituto de Ciências Biomédicas, Universidade de São Paulo, São Paulo, SP, Brasil

\section{Correspondence}

S.T. Casagrande

Seção de Bacteriologia

Instituto Adolfo Lutz

Av. Dr. Arnaldo, 351

01246-902 São Paulo, SP

Brasil

E-mail: casasil@ unisys.com.br

Publication supported by FAPESP.

Received March 3, 1999 Accepted December 17, 1999

\section{Abstract}

From 1989 to 1995, a total of 391 Haemophilus influenzae isolates were recovered from the cerebrospinal fluid (CSF) of hospitalized patients in São Paulo, Brazil. The majority of strains were isolated from infants aged less than 5 years. Strains belonging to biotype I (64.7\%), biotype II (34.5\%) and biotype IV (0.76\%) were detected. Ninety-nine percent of these strains were serotype b. Minimal inhibitory concentration (MIC) was determined for ampicillin, chloramphenicol and ceftriaxone. The $\beta$-lactamase assay was performed for all strains. The rate of $\beta$-lactamase producer strains ranged from 10 to $21.4 \%$ during a period of 7 years, with an overall rate of $13.8 \%$. Of the 391 strains analyzed, none was $\beta$-lactamase negative ampicillin resistant (BLNAR). A total of $9.7 \%$ of strains showed resistance to both ampicillin and chloramphenicol; however, $4 \%$ of them were resistant to ampicillin only and $2 \%$ to chloramphenicol. All strains were susceptible to ceftriaxone and the $\mathrm{MIC}_{90}$ was $0.007 \mu \mathrm{g} / \mathrm{ml}$, suggesting that ceftriaxone could be an option for the treatment of bacterial meningitis in pediatric patients who have not been screened for drug sensitivity.

\section{Introduction}

Meningitis, especially in infants, young children and in the elderly, is the most serious clinical manifestation of invasive disease caused by Haemophilus influenzae $(1,2)$. Substantial declines in invasive Haemophilus influenzae type $\mathrm{b}$ diseases have been reported in many countries where routine vaccination against $H$. influenzae type $\mathrm{b}$ has been implemented (3-6). Although very successful in developed countries, $H$. influenzae type $b$ vaccination is still very costly and

\section{Key words}

- Haemophilus influenzae

- Meningitis

- Antimicrobial resistance unfeasible in the majority of developing countries. In São Paulo State, Brazil, H. influenzae is the second most common cause of meningitis, mainly among infants aged less than 5 years. The average annual rate of incidence of meningitis caused by $H$. influenzae was 11.4 cases per 100,000 inhabitants from 1989 to 1995 (Respiratory Diseases Division, Epidemiological Surveillance Center, São Paulo, SP, Brazil).

Resistance to ampicillin due to a plasmid-mediated extracellular TEM-1 type $\beta$ lactamase was recognized in $H$. influenzae 
for the first time in 1974 (7-9). Subsequently, strains producing a second B-lactamase named ROB-1 enzyme were reported (10). More recently, $H$. influenzae strains referred to as B-lactamase negative ampicillin resistant (BLNAR) have also been described, although such strains seem to be relatively uncommon as shown by recent national and multinational surveillance studies $(2,11-14)$. The prevalence of ampicillin resistance in $H$. influenzae strains has been the subject of multinational surveillance studies in several countries and the overall rate reported was between 10 and $60 \%(8,9,11-14)$. The emergence of resistant $H$. influenzae strains, particularly to ampicillin, all over the world has limited the routine use of ampicillin and as a result third-generation cephalosporins have become a therapeutic option $(15,16)$.

Few data are available in Brazil on ampicillin resistance and B-lactamase production in $H$. influenzae isolated from young children. In the present study we report the antimicrobial resistance pattern of $H$. influenzae isolated chiefly from young children in São Paulo, Brazil, from 1989 through 1995.

\section{Material and Methods}

\section{Bacterial strains}

A total of $391 \mathrm{H}$. influenzae strains isolated between 1989 and 1995 were studied. All strains were isolated from cerebrospinal fluid (CSF) samples, $76 \%$ of them from infants aged less than 5 years and hospitalized in São Paulo municipality. These strains and CSF were sent by hospital laboratories to the National Center for Meningitis, Adolfo Lutz Institute, Central Public Health Laboratory, São Paulo, Brazil, for routine microbiological analysis.

\section{Strain identification}

Isolates were identified by colony and cell morphology and by the demonstration of growth requirements for $\mathrm{V}$ and $\mathrm{X}$ factors. The $\mathrm{V}$ requirement was tested by observing the satellite phenomenon and the $\mathrm{X}$ factor dependence was determined by testing the ability to convert $\delta$-aminolevulinic acid to porphyrins. Strains were further characterized by biochemical reactions using the method described by Kilian and Biberstein (17). Capsulated strains were serotyped by the method of Pitman (18) using slide agglutination with type-specific antisera a through $\mathrm{f}$.

\section{Susceptibility testing}

All strains were subcultured twice onto a chocolate agar plate (Difco Laboratories, Detroit, MI, USA) and incubated at $37^{\circ} \mathrm{C}$ in $5 \% \mathrm{CO}_{2}$ for $18-24 \mathrm{~h}$ before testing. The minimal inhibitory concentrations (MIC) of different antimicrobial agents were determined by the broth microdilution method using Haemophilus test medium (HTM) (Cationsupplemented Mueller-Hinton Broth, BBL Microbiology Systems, Cockeysville, MD, USA), supplemented with $15 \mu \mathrm{g} / \mathrm{ml}$ of bovine hematin, $15 \mu \mathrm{g} / \mathrm{ml}$ of NAD and $5 \mu \mathrm{g} / \mathrm{ml}$ of yeast extract (Difco Laboratories), containing one of the following antimicrobial agents at 2 -fold dilution: $0.03-32 \mu \mathrm{g} / \mathrm{ml}$ ampicillin, $0.015-16 \mu \mathrm{g} / \mathrm{ml}$ chloramphenicol, 0.001- $2 \mu \mathrm{g} / \mathrm{ml}$ ceftriaxone (19) (Sigma Chemical Co., St. Louis, MO, USA). Antibiotic panels were prepared by dispensing media containing two-fold concentration increments of antimicrobial agents in a $50-\mu 1$ volume into plastic 96-well trays (Difco). Growth from 18- to 24-h cultures was suspended in distilled water and diluted to match the turbidity, this being equivalent to $0.5 \mathrm{McF}$ arland standard read using a spectrophotometer at $625 \mathrm{~nm}$. The suspension was further diluted $1: 100$ and added to the dilution trays to achieve a final inoculum of $5 \times 10^{5} \mathrm{CFU} / \mathrm{ml}$.

Colony counts were performed to determine the desired final inoculum (19). Immediately following inoculation, the microdilution panel was incubated at $37^{\circ} \mathrm{C}$ in ambient 
air for 20 to $24 \mathrm{~h}$. After incubation the MIC was defined as the lowest concentration of an antimicrobial agent required for an organism to show no evidence of growth. According to the NCCLS criteria (19), the organisms were considered resistant/susceptible if the MIC was $\geq / \leq(\mu \mathrm{g} / \mathrm{ml}) 4 / 1$ for ampicillin and $8 / 2$ for chloramphenicol, and susceptible if the MIC was $\leq 2 \mu \mathrm{g} / \mathrm{ml}$ for ceftriaxone. Haemophilus influenzae ATCC 49247 was used as control.

\section{ß-Lactamase assay}

Production of $\beta$-lactamase was determined by the chromogenic cephalosporin method (7) using reconstituted lyophylized nitrocefin (Glaxo 87/312 Glaxo Research, Unipath Ltd., Hampshire, England). The test was considered positive if the color changed from yellow to purple for cephalosporin. Haemophilus influenzae ATCC 49247 was used as negative control and Staphylococcus aureus ATCC 29213 as positive control.

\section{Results}

\section{Biotypes and serotypes}

Strains belonging to biotype I 253
(64.7\%), biotype II 135 (34.5\%) and biotype IV $3(0.76 \%)$ were detected. Type $b$ was the serotype accounting for $99 \%$ of strains.

\section{Antimicrobial resistance patterns}

The annual percentage of resistant strains is shown in Table 1. The overall rate of ampicillin-resistant strains that produced $B$ lactamase was $13.8 \%$. The percentage of $\beta$ lactamase producer strains isolated was $14.0 \%$ for children aged less than 5 years and $1.6 \%$ for children older than 6 years. This difference was not statistically significant, as demonstrated by the chi-square test $(\mathrm{P}=$ $0.3)$. Resistance to both ampicillin and chloramphenicol was observed in 9.7\% (38/391) of strains. Strains isolated in 1993 showed the highest rate of $B$-lactamase-producing strains $(21.4 \%)$ and also of strains resistant to both chloramphenicol and ampicillin (14.2\%). The overall rate of strains resistant only to chloramphenicol was $2.0 \%$, and the overall rate of strains resistant only to ampicillin was $4.0 \%$. Among the 391 strains analyzed, none was BLNAR. Data concerning the $\mathrm{MIC}_{50}$ and $\mathrm{MIC}_{90}$ of B-lactamasepositive and -negative strains are summarized in Table 2. All H. influenzae strains were extremely susceptible to ceftriaxone,

\begin{tabular}{|c|c|c|c|c|c|}
\hline \multirow[t]{2}{*}{ Year } & \multirow{2}{*}{$\begin{array}{l}\text { No. of } \\
\text { strains }\end{array}$} & \multirow{2}{*}{$\begin{array}{c}\text { No. (\%) of } \\
\text { B-lactamase-positive }\end{array}$} & \multicolumn{3}{|c|}{ No. $(\%)$ of resistant strains ${ }^{1}$ to: } \\
\hline & & & ampicillin & chloramphenicol & chloramphenicol and ampicillin \\
\hline 1989 & 82 & 9 (10.9) & $3(3.6)$ & - & $6(7.3)$ \\
\hline 1990 & 72 & 9 (12.5) & $1(1.4)$ & $3(4.2)$ & $8(11.1)$ \\
\hline 1991 & 85 & $10(11.7)$ & $3(3.5)$ & $1(1.2)$ & $7(8.2)$ \\
\hline 1992 & 63 & $10(15.9)$ & $3(4.8)$ & $1(1.5)$ & 7 (11.1) \\
\hline 1993 & 42 & $9(21.4)$ & $3(7.1)$ & $1(2.4)$ & $6(14.2)$ \\
\hline 1994 & 27 & $4(15.0)$ & $1(3.7)$ & $1(4.0)$ & $3(11.1)$ \\
\hline 1995 & 20 & $3(15.0)$ & $2(10.0)$ & $1(5.0)$ & $1(5.0)$ \\
\hline Total & 391 & $54(13.8)$ & $16(4.0)$ & $8(2.0)$ & $38(9.7)$ \\
\hline
\end{tabular}


exhibiting $\mathrm{MIC}_{90}$ values of $0.007 \mu \mathrm{g} / \mathrm{ml}$ (Table 2).

\section{Discussion}

Since the late 1970's, antibiotic resistance has increased among strains of $H$. influenzae, mainly in terms of B-lactamasemediated ampicillin resistance, representing a serious clinical concern all over the world. The present study shows that the overall rate of B-lactamase producers in $H$. influenzae was $13.8 \%$. Similar results have also been obtained in a collaborative study conducted in the US during the 80's and in São Paulo during the 90's (20,21). In Finland and in South Africa the overall rate of $\beta$-lactamasemediated ampicillin resistance in $H$. influenzae was $10 \%(11,22,23)$.

The $\beta$-lactamase-producing strains presented a $\mathrm{MIC}_{90}$ of $32 \mu \mathrm{g} / \mathrm{ml}$ for ampicillin and $16 \mu \mathrm{g} / \mathrm{ml}$ for chloramphenicol, with most strains resistant to ampicillin being also resistant to chloramphenicol (Table 1). The resistance to ampicillin is coded by a plasmid which harbors the transposon TnA, and the transposition mechanism is important for the evolution to plasmids simultaneously carrying multiple resistance $(24,25)$. Significant changes in $\mathrm{MIC}_{90}$ values over a period of time could be the best indicators of increasing resistance to the B-lactam antibiotics in $H$. influenzae (24).

The overall rates of ß-lactamase production were highest in the age groups of less than 5 years and among isolates from sys- temic sources such as CSF. These observations could be explained by the relatively higher percentage of $H$. influenzae strains isolated from young children. Non- $\beta$-lactamase-mediated ampicillin resistance was not detected among the $H$. influenzae strains studied. This is in agreement with numerous previous surveillance studies, which have indicated that such observations remain uncommon $(11,13,14)$. It has been postulated that BLNAR is associated with altered penicillin-binding proteins (PBPs) and might be due to a lower virulence of strains with abnormal PBPs $(13,16,26)$.

Although in the 80's it was reported that $57 \%$ of $H$. influenzae strains isolated in Spain were ampicillin and chloramphenicol resistant, resistance to chloramphenicol only is still rare $(8,9,14,21)$. Among our strains, $11.7 \%$ were resistant to chloramphenicol, including the associated resistance to ampicillin $(9.7 \%$ ), and $2 \%$ were resistant only to chloramphenicol. In addition, $\mathrm{MIC}_{90}$ to chloramphenicol showed the same range (8-16 $\mu \mathrm{g} / \mathrm{ml})$, in agreement with data reported in other countries $(8,27)$. Our data indicate that $9.7 \%$ of all strains were resistant both to ampicillin and chloramphenicol, in agreement with reported results (21).

The rapid detection of resistance and early initiation of alternative therapy are important factors in the treatment of meningitis caused by multiple resistance strains. It is of fundamental importance to perform the $\beta$ lactamase test and susceptibility tests in order to detect resistance to ampicillin and

Table 2 - MIC $_{50}$ and MIC $_{90}$ of ß-lactamase-positive and -negative H. influenzae strains isolated from CSF in São Paulo, Brazil, between 1989 and 1995.

\begin{tabular}{|c|c|c|c|c|c|c|}
\hline & \multicolumn{2}{|c|}{ ß-Lactamase-positive } & \multirow[t]{3}{*}{ Range } & \multicolumn{2}{|c|}{ ß-Lactamase-negative } & \multirow[t]{3}{*}{ Range } \\
\hline & $\mathrm{MIC}_{50}$ & $\mathrm{MIC}_{90}$ & & $\mathrm{MIC}_{50}$ & $\mathrm{MIC}_{90}$ & \\
\hline & \multicolumn{2}{|c|}{$(\mu \mathrm{g} / \mathrm{ml})$} & & \multicolumn{2}{|c|}{$(\mu \mathrm{g} / \mathrm{ml})$} & \\
\hline Ampicillin & 16 & 32 & $2-32$ & 0.125 & 0.25 & $0.06-0.25$ \\
\hline Chloramphenicol & 8.0 & 16 & 8-16 & 0.5 & 1.0 & $0.03-1.0$ \\
\hline Ceftriaxone & 0.003 & 0.007 & $0.001-0.007$ & 0.003 & 0.007 & $0.001-0.007$ \\
\hline
\end{tabular}


chloramphenicol. No relationship between antimicrobial resistance patterns and biotypes was seen in our study, as also reported elsewhere $(23,28)$. We observed a higher frequency of biotype I among strains isolated from invasive disease mainly affecting children, as also reported previously (29).

All strains were susceptible to ceftriaxone with a $\mathrm{MIC}_{90}$ of $0.007 \mu \mathrm{g} / \mathrm{ml}$ for B-lactamase-positive and -negative strains. In developed countries, the alternative treatment of choice for meningitis caused by multiple resistant $H$. influenzae strains is the use of third-generation cephalosporins (11-13). In several countries resistance to ampicillin and chloramphenicol was found to be sufficiently high to warrant their replacement by a combination of ampicillin with a ß-lactamase inhibitor, e.g., sulbactam or a third-generation cephalosporin as first-line therapy, depending on the severity of infection $(8,15,22$ 24).

In Brazil there is a need for further evaluation of the resistance profile in $H$. influenzae to ensure a better therapy option, especially where the combination of ampicillin and chloramphenicol is extensively applied because of its low cost and effectiveness $(23,30,31)$.

The emergence of drug resistance is a serious challenge for the management of invasive $H$. influenzae disease, which em- phasizes the fundamental role of laboratorybased surveillance for antimicrobial resistance. The continued usefulness of antimicrobial agents will probably depend on the rational use of antimicrobial agents in the community.

We showed an increasing antimicrobial resistance to ampicillin and chloramphenicol among Haemophilus influenzae strains isolated from children. Since all strains were susceptible to ceftriaxone, we conclude that this antimicrobial agent could be an option for the treatment of bacterial meningitis in pediatric patients who have not been screened for drug sensitivity.

\section{Acknowledgments}

We thank Dr. Kinue Irino for useful comments and for revising the manuscript, and Dr. Eliseu Waldman for advice regarding the manuscript. We are also indebted to Dr. Carmo Elias A. Melles, Meningitis Reference Center Coordinator, for valuable assistance, to Maria C. Cunto Brandeleone for encouragement, and to Rosemeire Cobo Zanella for supplying the antisera. We acknowledge the State Hospital network for promptly sending the strains and cerebrospinal fluid samples, many of them received from Instituto de Infectologia Emílio Ribas.

\section{References}

1. J ordens J Z \& Slack MPE (1995). Haemophilus influenzae: Then and now. European J ournal of Clinical Microbiology and Infectious Diseases, 14: 935-948.

2. Scriver SR, Hoban DJ , McGeer A, Moore TC, Walmsley SL \& Low DE (1994). Surveillance of susceptibility testing methodologies for Haemophilus influenzae in Canada, including evaluation of disk diffusion test. J ournal of Clinical Microbiology, 32: 2013-2015.

3. Peltola H, Kilpi T \& Anttila M (1992). Rapid disappearance of Haemophilus influenzae type $b$ meningitis after routine childhood immunisation with conjugate vaccines. Lancet, 340: 592-594.

4. Adams WG, Deaver KA, Cochi SL, Plikaytis BD, Zell ER, Broome CV, Wenger J $D$ \& the Haemophilus influenzae Study Group (1993). Decline of childhood Haemophilus influenzae type $b$ (Hib) disease in the Hib vaccine era. J ournal of the American Medical Association, 269: 221226.

5. Teare EL, Fairley CK, White J \& Begg NT (1994). Efficacy of Hib vaccine. Lancet, 344: 828-829.

6. Wenger J D (1994). Impact of Haemophi- lus influenzae type $b$ vaccines on the epidemiology of bacterial meningitis. Infectious Agents and Diseases, 2: 324-332.

7. Sykes RB (1978). Methods for detecting betalactamase. In: David SR, Ian P, David W \& Richard W (Editors), Laboratory Methods in Antimicrobial Chemotherapy. Churchill Livingstone, Edinburgh, 64-69.

8. Campos J, Torne SG, Gairi J MJ \& Fabregues I (1986). Multiple resistant Haemophilus influenzae type b causing meningitis: Comparative clinical and laboratory study. J ournal of Pediatric, 108: 897-902. 
9. Bijlmer HA, van Alphen L, Greenwood BM, van den Broek LG, Valkenburg HÁ \& Dankert J (1994). Antibiotic susceptibility of invasive and non-invasive isolates of Haemophilus influenzae from the Gambia, West Africa. J ournal of Antimicrobial Chemotherapy, 34: 275-280.

10. Markowitz SM (1980). Isolation of ampicillin resistant production strain of Haemophilus influenzae. Antimicrobial Agents and Chemotherapy, 17: 80-83.

11. J orgensen JH, Doern GV, Maher LA, Howell AW \& Redding J A (1990). Antimicrobial resistance among respiratory isolates of Haemophilus influenzae, Moraxella catarrhalis, and Streptococcus pneumoniae in the United States. J ournal of Clinical Microbiology, 34: 2075-2080.

12. Powell M, McVey D, Kassim MH, Chen HY \& Williams JD (1991). Antimicrobial susceptibility of Streptococcus pneumoniae, Haemophilus influenzae and Moraxella (Brahamella) catarrhalis isolated in the UK from sputa. J ournal of Antimicrobial Chemotherapy, 28: 249-259.

13. Nissinen A, Herva E, Katila ML, Kontiainen S, Liimatainen O, Oinonen S, Takala AK \& Huovinen P (1995). Antimicrobial resistance in Haemophilus influenzae isolated from blood, cerebrospinal fluid, middle ear fluid and throat samples of children. A nationwide study in Finland in 1988-1990. Scandinavian J ournal of Infectious Diseases, 27: 57-61.

14. Doern GV \& the Alexander Project Collaborative Group (1996). Antimicrobial resistance among lower respiratory tract isolates of Haemophilus influenzae: results of a 1992-93 Western Europe and USA collaborative surveillance study. J ournal of Antimicrobial Chemotherapy, 38: 59-69.

15. Bryan J P, Silva HR, Tavares A, Rocha L \& Sheld WM (1990). Etiology and mortality of bacterial meningitis in Northeastern Brazil. Reviews of Infectious Diseases, 12: 128-135.

16. Williams J D \& Moosdeen J (1986). Antibiotic resistance in Haemophilus influenzae: epidemiology, mechanisms, and therapeutic possibilities. Reviews of Infectious Diseases, 8: S555-S561.

17. Kilian $M \&$ \& Biberstein EL (1984). Haemophilus. In: Noel RK \& J ohn GH (Editors), Bergey's Manual of Systematic Bacteriology. Williams \& Wilkins, Baltimore, USA, 558-569.

18. Pitman M (1931). Variation and type specificity in the bacterial species Haemophilus influenzae. J ournal of Experimental Medicine, 53: 471-492.

19. National Committee for Clinical Laboratory Standards (NCCLS) (1997). Performance standards for antimicrobial susceptibility testing. 4th edn. Information Suppl M100 S5. Approved standard. NCCLS, Vilanova, PA.

20. Doern GV, J orgensen J H, Thornsberry C, Preston DA \& the Haemophilus influenzae Surveillance Group (1986). Prevalence of antimicrobial resistance among clinical isolates of Haemophilus influenzae: a collaborative study. Diagnostic Microbiology and Infectious Diseases, 4: 95-107.

21. Rey LC \& Farhat CK (1997). Prevalência de Haemophilus influenzae resistentes a ampicilina, cefaclor, cefotaxime, cloranfenicol e cotrimoxazol isolados de laboratórios na cidade de São Paulo. J ornal de Pediatria, 73: 26-31.

22. Manninen $R$, Huovinen $P$, Nissinen $A \&$ Finnish Study Group for Antimicrobial Resistance (1997). Increased antimicrobial resistance in Streptococcus pneumoniae, Haemophilus influenzae and Moraxella catarrhalis in Finland. J ournal of Antimicrobial Chemotherapy, 40: 387-392.

23. Hussey G, HitchcockJ, Hanslo D, Coetzee
G, Van Shalkwyk E, Pitout J \& Schaaf H (1994). Serotypes and antimicrobial susceptibility of Haemophilus influenzae. J ournal of Antimicrobial Chemotherapy, 34: 1031-1036.

24. J ames PA, Lewis DA, J ordens J Z, Cribb J Dawson SJ \& Murray SA (1996). The incidence and epidemiology of ß-lactam resistance in Haemophilus influenzae. J ournal of Antimicrobial Chemotherapy, 37: 737-746.

25. Brunton J , Clare D \& Meier MA (1986). Molecular epidemiology of antibiotic resistance plasmids of Haemophilus species and Neisseria gonorrhoeae. Reviews of Infectious Diseases, 8: 713-724.

26. Rubin LG, Mendelman PM, Rakita RM \& Rosen H (1991). Virulence of non-ß-lactamase-mediated ampicillin-resistant Haemophilus influenzae. FEMS Microbiological Letters, 84: 27-32.

27. Givner LB, Abramson J S \& Wasilauskas B (1989). Meningitis due to Haemophilus influenzae type $b$ resistant to ampicillin and chloramphenicol. Reviews of Infectious Diseases, 11: 329-334.

28. Long SS, Teter MJ \& Gilligan PH (1983). Biotype of Haemophilus influenzae: correlation with virulence and ampicillin resistance. J ournal of Infectious Diseases, 147: 800-806

29. Landgraf IM \& Vieira MFP (1993). Biotypes and serotypes of Haemophilus influenzae from patients with meningitis in the city of São Paulo, Brazil. J ournal of Clinical Microbiology, 31: 743-745.

30. Guia de Vigilância Epidemiológica (1998). Meningites em geral (Cap. 5.20). Ministério da Saúde. Fundação Nacional de Saúde, Brasília.

31. Freire HBM \& Freire LMS (1994). Aspectos atuais do tratamento das meningites bacterianas. Revista Médica de Minas Gerais, 4: 37-38. 